\title{
Inhalt
}

Vorwort Seite

Inhaltsverzeichnis und Gedichtanfänge . . . . . . . . . . . V

1. Die Voraussetzungen in Kinkels Entwickiung bis 1839 . . . . 1

2. Die Düsseidorfer Schule, der Kunstverein und Künstiervereinigungen 6

3. Otto Mengelberg . . . . . . . . . . . . . . . . . 12

4. Josef Fay . . . . . . . . . . . . . . . . . . . . 21

5. Kinkel in Köln und Düsseldorf und seine gesellige Art. . . . 31

6. Ausgewählte Gedichte . . . . . . . . . . . . . . . 37

Lyrisches . . . . . . . . . . . . . . . . . . 38

Dürre Blätter des Südens . . . . . . . . . . . . . 47

Geistliche Gedichte . . . . . . . . . . . . . . . 49

Sprüche und Distichen . . . . . . . . . . . . . . . . 59

Sprüche . . . . . . . . . . . . . . . . . 60

Distichen . . . . . . . . . . . . . . . . . . 64

Inschriften zu Antiken . . . . . . . . . . . . . 65

Romanzen und Legenden . . . . . . . . . . . . . 69

7. Anmerkungen und Erläuterungen . . . . . . . . . . . 83

\section{Anfänge der neugedruckten Gedichte}

Alle Blumen sind da. . . . . . . . . . . . . . . . . 65

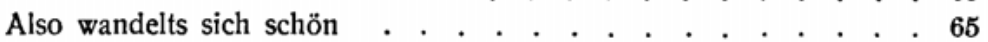

Anadyomene, Bild aus kaltem . . . . . . . . . . . . . . 66

Auf aller Erde ruht ein stiller Friede . . . . . . . . . . . 50

Beide sich zärtlich umarmend . . . . . . . . . . . . . . 65

Der Tag ist schwül, es ruht die Herde . . . . . . . . . . 78

Diese Nacht in deinen Armen . . . . . . . . . . . . 75

$\mathrm{Ei}$, was frag ich danach . . . . . . . . . . . . . . . 41

Entsetzlich lang, entsetzlich bang . . . . . . . . . . . . 56

Erst sangen sie nur in alten Weisen . . . . . . . . . . . 61

Erzählenden Stoff, von der Sage gegeben . . . . . . . . . 61

Freiwerber trat hinein ins Haus . . . . . . . . . . . . . 72

Fürst Wilhelm von Nassau . . . . . . . . . . . . . . . 60

Furchtbar mahnet dein Los . . . . . . . . . . . . . . 66 
Gar mannigfach ist wahrer Dichtung Farbe . . . . . . . . 39

Glocken hallen . . . . . . . . . . . . . . . . . . 76

Großes hat Zeus dir getan . . . . . . . . . . . . . . 66

Hegst du wirkliche Trene . . . . . . . . . . . 67

Hin und tot! Laut jauclizet das Volk . . . 67

Höre zu schleifen doch auf . . . . . . . . . . . . . . 66

Ich kann es nicht ermessen noch begreifen . . . . . 51

Ich nenn' ein Nichts das arme. . . . . . . . . . . . . 44

Im Schlosse zu Düsseldorf wirbelt der Tanz. . . . . . . . $\quad 70$

In dem Schilf des Unkenteiches ${ }^{1}$ ). . . . . . . . . . . 73

In weiblichen Herzen hat leichter ein Schatz . . . . . . . . 63

Kann man ein neckischer Bild. . . . . . . . . . . . . . 64

Keine kokettere Blume . . . . . . . . . . . . . . . 64

Keuscheste Göttin des Herds . . . . . . . . . . . . . 66

Lieblich klagendes Bild . . . . . . . . . . . . . . . . 64

Mein Freund, ich bin so dumpf . . . . . . . . . . . . . 42

Nennet nur mein Leben stürmisch . . . . . . . . . . . . 60

O Himmelsjungfrau mit den deutschen Sitten . . . . . . . . . 43

$\mathrm{O}$, von der Erde auf, nicht trag ichs länger. . . . . . . . . 52

Schlafe reizender Knabe . . . . . . . . . . . . . . . . $\quad 67$

Sei stark, sei stark und stille . . . . . . . . . . . . . . . . 39

Sonst war ein jeder sentimental . . . . . . . . . . . . . 61

Stolz, wie ein älteres Mädchen. . . . . . . . . . . . . 64

Vieles lehrtest du sie . . . . . . . . . . . . . . . 65

Viel schreibst du, wenn Liebchen bei dir ist. . . . . . . . . 62

Vollendet ist des Tages Mühe . . . . . . . . . . . . . . 53

War ein Röschen in voller Blüt . . . . . . . . . . . . . 72

Was das Leben mir verwehrte . . . . . . . . . . . . . 60

Weil verstümmelt du kamst. . . . . . . . . . . . . . . 65

Wenn die Azalia heiß. . . . . . . . . . . . . . . . 64

Wie oft, o Heiland, hab ich dich gemieden . . . . . . . . . 5I

Wieviel des Segens habe ich genossen . . . . . . . . . . 50

Willst Wein du trinken . . . . . . . . . . . . . . 60

Zu dir, o Herr, will auf mein Herz sich ranken . . . . . . . 52

Zu Lukka in Italia.. . . . . . . . . . . . . . . . . 74

1) Nachträglich stellt sich heraus, dass diese „Froschromanze“ vorübergehend schon mitgeteiit ist in der 3., von Johanna besorgten, Ausgabe der Gedichte von 1851, S. $45 \mathrm{f}$. Abweichungen: 2, 5: tapfer alle. 3, 3,4: In die hohe Seele schneidet Ilım das. 4, 4: der Wunde. 5, 4: führt die. 6, 3: selig koaxend. 